\title{
Mensaje del presidente
}

Message from the president

Mensagem do presidente

Julio César Mijangos Méndez*

Es para mí un honor y un gran privilegio poder servir como Presidente del Consejo Directivo del Colegio Mexicano de Medicina Crítica, A.C. para el bienio 2021-2022, una institución con cerca de 48 años de vida ininterrumpida, fundada por un grupo de médicos visionarios originalmente con el nombre de Asociación Mexicana de Medicina Crítica y Terapia Intensiva (AMMCTI), bajo el liderazgo del Dr. Alberto Villazón Sahagún, quien fue además un impulsor de la colaboración internacional y «un verdadero líder del mundo de los cuidados intensivos", tal y como fue descrito en su reseña In memoriam publicada en la revista Critical Care Medicine. ${ }^{1}$

Sabemos lo difícil que fue el 2020 para todo el personal de salud y lo complejo de los primeros meses de este nuevo año debido a la pandemia por COVID-19, en especial para quienes dedicamos nuestra labor a las área críticas con los enfermos más graves; por ello, en primera instancia, deseo expresar mi más respetuoso reconocimiento a su noble quehacer, dedicación, entrega y coraje para enfrentar con valentía y entereza esta amenaza, aun a costa de su propia integridad. De manera especial, deseo brindar nuestra gratitud por siempre para quienes desafortunadamente perdieron la vida en esta batalla, a sus familias y amigos toda nuestra solidaridad y afecto.

Los desafíos que como sociedad en conjunto enfrentamos, pusieron de manifiesto nuestra capacidad de adaptación y transformación en distintos ámbitos de nuestras vidas, tanto de manera colectiva como individual. El Colegio Mexicano de Medicina Crítica no estuvo ajeno a estos cambios, y con toda responsabilidad y compromiso generó los espacios y canales necesarios para poder continuar con su labor, habiendo realizado así un desempeño excepcional, organizando sesiones académicas en línea con colegas intensivistas líderes de diversos países alrededor del mundo como China, Estados Unidos, Italia y España, por mencionar algunos, tras lo cual se logró un intercambio de experiencias enriquecedor en relación con la atención de pacientes críticos con infección por SARS-

\footnotetext{
* Presidente del Consejo Directivo del Colegio Mexicano de Medicina Crítica.
}

Citar como: Mijangos MJC. Mensaje del presidente. Med Crit. 2021;35(1):6-7. https:// dx.doi.org/10.35366/99146

www.medigraphic.com/medicinacritica
CoV-2. Ante la necesidad de suspender el congreso presencial para el año 2020, el Colegio Mexicano de Medicina Crítica tomó la decisión de realizar el primer congreso en modalidad virtual de su historia, cuyo éxito fue indiscutible tras lograr una participación que rondó los 4,500 asistentes, con un número histórico de participación de profesores tanto nacionales como extranjeros. ${ }^{2}$

El trabajo del Consejo Directivo 2021-2022 dará continuidad a la tarea realizada por las administraciones previas con relación en la estructura organizacional del colegio; pondremos especial atención para mantener una cercanía con sus miembros y sus respectivos colegios, al igual que con asociaciones estatales de medicina crítica, facilitando los servicios que el propio colegio les brinda, además de generar los canales de comunicación y colaboración necesarios para ello. El desarrollo de los grupos de trabajo del colegio (capítulos) será uno de los compromisos de esta administración, fortaleciendo sus estructuras de tal modo que cada uno de ellos logre consolidarse.

Es de especial interés incentivar la participación de los intensivistas en formación en las actividades académicas del colegio, además de fomentar en ellos la actividad de investigación en el área de los cuidados críticos, para lo cual, el colegio debe crear los espacios para que se logre el desarrollo de dichas actividades y se consoliden; como un inicio, se pueden fortalecer actividades básicas como la lectura crítica y la medicina basada en evidencia en cuidados críticos. Con la idea de llevar al colegio a tener una presencia y oferta académica más diversa e innovadora, se ampliarán las opciones de tecnologías de la información que actualmente se utilizan como el uso de podcast, webinars, aplicaciones móviles y plataformas digitales.

El trabajo colaborativo y liderazgo del colegio a nivel internacional ha quedado de manifiesto en actividades como la asistencia a estudios multicéntricos con sociedades internacionales, o con la participación de distinguidos miembros del colegio como parte de las mesas directivas de sociedades, tales como la Federación Panamericana de Medicina Crítica y Terapia Intensiva (FEPIMCTI) y la World Federation of Intensive and Critical Care (WFICC); por tal motivo, seguiremos impulsando la proyección y representación del colegio y sus miembros en el ámbito internacional. 
Para esta gestión, deseamos llevar a cabo un trabajo que se caracterice por mantenernos juntos: consejo directivo y socios, en unidad y por un futuro de innovación para el Colegio Mexicano de Medicina Crítica que, sumado al trabajo de todos, lo lleve a consolidarse como una institución de liderazgo en la Medicina Crítica en el mundo, tal y cual fue el sueño de sus fundadores.

\section{REFERENCIAS}

1. Bryan-Brown CW, Grenvik ANA. Alberto Villazón Sahagún, MD, December 15, 1925-March 15, 2001. Crit Care Med. $2001 ; 29(11): 2045$.

2. Zaragoza-Galván JJ. Reseña del XLVII Congreso del Colegio Mexicano de Medicina Crítica. Med Crit. 2020;34(6):350-351.

Correspondencia:

Julio César Mijangos Méndez

E-mail: julio.mijangos@gmail.com 